\title{
PROCEDIMENTOS ENVOLVENDO A COMISSÃO DE NOVOS MINERAIS E NOMES DE MINERAIS DA IMÃ, E DIRETRIZES SOBRE NOMENCLATURA MINERAL
}

\author{
ERNEST H. NICKEL* e JOSEPH A. MANDARINO**
}

\begin{abstract}
Tradução e adaptação do original em inglês "PROCEDURES INVOLVING THE IMA COMMISSION ON NEW MINERALS AND MINERAL NAMES; AND GUIDELINES ON MINERAL NOMENCLATURE", [publicado nos seguintes periódicos: Ada Petrologica et Minenúogka 6(1987):252-278, American Mineralogist 72(1987): 1031-1042, Boletfn de Ia Sociedad Espafiola de Mineralogfa 12(1989):1-30, Bulletin de Mineralogie 110(1987):717-741, Canadian Mineralogist 25(1987):353-377, Fortschrifte der Mineralogie 65(1987):175-196, Indian Journal of Earth Sciences 14(1987):152-188, Míneralogical Journal 13(1987):505-532, Mineralogfcal Magazine 52(1988):275-292, Mineralogy and Petrology 37(1987):157-179, Mineralogicheskiy Zhumal 11(1)(1989):51-86, Recooditi delia Società Italiana di Mineralogia e Petrologia 4(1988):27-53, Riyista Mineralogies Italiana 1:5-31 (Supl.), Schweizerische Mineralogische und Petrographische Mitteillungen 67(1/2): 185-210], realizada com a permissão da IMA por
\end{abstract}

DANIEL ATENCIO*»* e GIANNA MARIA GARDA*****

\begin{abstract}
PROCEDURES INVOLVING THE IMA. COMMISSION ON NEW MINERALS AND MINERAL NAMES, AND GUIDELINES ON MINERAL NOMENCLATURE. An author wishing to introduce a new mineral name into the literature, or to redefine, discredit or rename an existing mineral, must obtain prior approval of the IMA Commission on New Minerals and Mineral Names. This paper outlines die procedure to be followed in the preparation and submission of a proposal far approval, and describes how such proposals are handled by the Commission. The paper also reports decisions on nomenclature made by the Commission, and gives general guidelines on mineral nomenclature. Lists of mineral names discredited by the Commission, and of recently-approved rare-earth mineral names are appended.
\end{abstract}

Keywords: New minerais, mineral names, redefinition, discreditatkm and invalidation of minerals.

\begin{abstract}
RESUMO Um autor que desejar introduzir um novo nome de mineral naUteratura, ou redefinir, desacreditar ou rebatizar um mineral existente, deverá obter aprovação prévia da comissão de Novos Minerais e Nomes de Minerais da IMÃ. Este artigo esquematiza os procedimentos a serem seguidos na preparação e . submissão de uma propostas para aprovação, e descreve como tais propostas slo tratadas pela Comissão. Este artigo também inclui decisões sobre nomenclatura tomadas pela Comissão, e apresenta diretrizes gerais sobre nomenclatura mineral. Listas de nomes de minerais desacreditados pela Comissão e de nomes de minerais de terras raras recentemente aprovados são anexadas.
\end{abstract}

Palavras-chaves: Novos minerais, nomes de minerais, redefinição, descrédito e revalidação de minerais.

INTRODUÇÃ̃O A Comissão de Novos Minerais e Nomes de Minerais (CNMMN) da Associação Mineralógica Internacional (IMÃ) foi estabelecida em 1959, com o propósito de controlar a nomenclatura mineral. Todas as propostas para introduzir novos minerais, modificar a nomenclatura mineralógica e desacreditar ou redefinir minerais existentes e nomes de minerais devem ser submetidas à CNMMN para aprovação antes da publicação. Se a aprovação não for concedida, a proposta não deverá ser publicada.

Este trabalho incorpora matérias de publicações prévias sobre nomenclatura e procedimentos da CNMMN (Fleischer 1970, Donnay \& Fleischer 1970, Embrey \& Hey 1970, Hey \& Gottardi 1980 e Mandarine et al. 1984), e representa uma tentativa de consolidar tal informação e apresentar um resumo completo do assunto. Quando houver diferenças entre o presente trabalho e os anteriores, esta versão deve ser considera,da como a correta.

\section{SUBMISSÃO DE PROPOSTAS}

a. Se a proposta tratar de um novo mineral, deverá ser encaminhada diretamente ao presidente da CNMMN. Em países onde se requer uma revisão prévia por sua delegação nacional, as propostas deverão ser primeiramente submetidas a esta delegação e subseqüentemente à CNMMN.

b. Todas as propostas para redefinição ou descrédito de minerais ou nomes de mineiras existentes, ou para revalidação de nomes obsoletos, devem ser submetidas ao vice-presidente da CNMMN, com uma cópia ao presidente.

c. Se a proposta tratar de grupo de minerais, deverá ser enviada ao secretário da CNMMN, com uma cópia ao presidente (o atual secretário é o Dr. Charles E.S. Arps, National Museum of Natural History, P.O. Box 9517, 2300 RA, Leiden, The Netherlands).

NATUREZA DA PROPOSTA Uma proposta deve incluir tantos dados quanto possíveis para que a CNMMN possa julgar adequadamente a validade da mesma. Idealmente, uma proposta de novo mineral deve conter as seguintes informações:

Nome proposto e razão para sua seleção.

* Vice-Prewidente da IM A-CNMMN. Division of Minerals and Geochemistry CSIRO, Private Bag, P.O., Wembley, W. A. Australia 6014

** Presidente da IMA-CNMMN. Departament of Mineralogy and Geology Royal Ontario Museum, 100 Queen's Park, Toronto, Ontario, Canada M5S 2C6

*** Representante brasileiro da IMA-Commission on New Minerals and Mineral Names. Departamento de Mineralogia e Petrologia, Instituto de Geociências, Universidade de Sfici Pauto, Caixa Postal 20899, CEP 01498, São Paulo, SP, Brasil

**** Departamento de Mineralogia e Petrologia, Instituto de Geociências, Universidade de São Paulo, Caixa Postal 20899, CEP 01498, Sàb Paulo, SP, Brasil 
Descrição da ocorrência (ocorrência geográfica e geológica, paragênese, e uma lista de minerais associados, particularmente aqueles em equilíbrio aparente com o novo mineral).

\section{Composição química e métodos de análise.}

\section{Fórmula química: empírica e simplificada.}

Cristalografia: sistema cristalino, classe cristalina, grupo espacial, parâmetros da cela unitária, volume da cela unitária, número de unidades de fórmula por cela unitária, dados de duração de raios $\mathrm{X}$, morfologia e estrutura cristalina.

Aspecto geral e propriedades físicas: tamanho de grãos ou cristais, tipo de agregado, cor, cor do traço, brilho, trasparência, dureza, tenacidade, clivagem, partição, fratura, densidade (calculada e medida).

\section{Propriedades ópticas}

a. Minerais não-metálicos: caráter óptico (isótropo ou anisótropo; uniaxial ou biaxial), sinal óptico, índices de refração, $2 \mathrm{~V}$, dispersão, orientação, pleocroismo e absorção.

b. Minerais metálicos: cor sob luz refletida, reflexões internas, anisotropia, birreflectância, pleocroismo e refletividade.

Material tipo (museu onde está depositado).

\section{Relação a outras espécies}

Quaisquer outros dados que esclareçam partes diflcies da descrição

Reconhece-se que nem sempre será possível obter todos os dados mencionados; nestes casos, o autor deve explicar as razões para as omissões. Para auxiliar autores potenciais de propostas de novos minerais, cópias da lista de verificação oficial podem ser obtidas com o presidente da CNMMN ou com um dos representantes nacionais. Instruções sobre alguns aspectos de propostas de minerais são fornecidas a seguir.

\section{CRITÉRIOS PARA UM NOVO NOME DE MINERAL}

Considerações Gerais Um mineral é geralmente aceito como sendo uma substância cristalina com limites composicionais definidos, e que foi formada como resultado de processos geológicos. Os componentes essenciais na definição de um mineral são sua composição química e suas propriedades cristalográficas. Se for encontrado um mineral de composição química e/ou com propriedades cristalográficas substancialmente diferentes daquelas de qualquer mineral existente, um novo nome, se necessário, deverá ser proposto à CNMMN. É provavelmente indesejável formular regras rígidas para definir quando ou não uma diferença composicional ou cristalográfica é suficientemente grande para requerer um novo nome de mineral, e cada proposta de mineral novo precisa ser considerada por seus próprios méritos. Porém, uma orientação geral para critérios composicionais é que pelo menos uma posição estrutural principal deve ser ocupada por um componente químico diferente daquele que ocorre em posição equivalente num mineral existente. Mas se a presença de um elemento que ocorre em quantidade relativamente menor estabiliza a estrutura, ou se sua presença em uma posição ocupada força uma mudança estrutural devido a diferença de carga ou de tamanho, então uma proposta para criação de um novo nome para tal mineral deverá ser levada em consideração. Genericamente falando, uma diferença cristalográfica suficientemente grande para justificar a criação de um novo nome de mineral é aquela em que a estrutura do mineral é topologicamente diferente de uma já existente.

Exemplo: Hidroxilapatita e fluorapatita cristalizam ambas no sistema hexagonal, com o mesmo grupo espacial, e têm parâmetros de cela unitária similares. São consideradas espécies minerais distintas pois a posição estrutural relevante é predominantemente ocupada por $\mathrm{OH}$ na hidroxilapatita e por $\mathrm{F}$ na fluorapatita.

Exemplo: Esfalerita (ZnS) e "marmatita" ([Zn, Fe]S) são ambas cúbicas com o mesmo grupo espacial e parâmetros de cela unitária similares, mas não são consideradas espécies minerais distintas, pois a posição estrutural do metal é ocupada predominantemente por $\mathrm{Zn}$ em ambos os casos. A "marmatita" é considerada variedade de esfalerita com $\mathrm{Fe}$ (II). Exemplo: Grafita e diamante têm a mesma composição química, mas suas estruturas são topologicamente diferentes e, conseqüentemente, merecem nomes distintos.

Polimorfos Os minerais polimorfos são aqueles que têm essencialmente a mesma composição química, mas diferentes estruturas cristalinas. Polimorfos são considerados espécies distintas e recebem nomes diferentes. Se as estruturas dos polimorfos são topologicamente similares, é preferível dar ao novo polimorfo um nome que esteja relacionado com o do polimorfo existente (ver "Seleção de um nome de mineral", a seguir) ao invés de atribuir a ele um.nome trivial.

Politipos Politipos foram definidos como substâncias que ocorrem em várias modificações estruturais diferentes, cada uma das quais podendo ser considerada constituída pelo empilhamento de camadas de estrutura e composição quase idênticas, e com as modificações diferindo apenas na seqüência de empühamento (Guilder et al. 1984). Politipos não recebem novos nomes, mas podem ser distinguidos por sufixos apropriados. A notação Gard modificada, recomendada pela União Internacional de Cristalografia (Guinier et al. 1984), é provavelmente mais detalhada do que deveria para a nomenclatura mineralógica, já que é necessário geralmente apenas distinguir entre politipos, e não especificá-los acuradamente. Conseqüentemente, uma nomenclatura simplificada, primeiramente proposta por Ramsdell (1947), que consiste de um sufixo em itálico compreendendo uma letra para indicar o sistema cristalino e um número para indicar a multiplicidade da unidade estrutural, é comumente usada. Os caracteres alfabéticos recomendados pela União Internacional de Cristalografia (Guinier et al. 1984), e agora pela CNMMN, são os seguintes: cúbico $=C$

hexagonal $=H$

romboédrico $=R$

írigonal $=T$

tetragonal $=Q$ (quadrático)

ortorrômbico $=O$

monoclfnico $=M$

triclfnico $=A$ (anórtico)

Exemplo: Wurtzita-4H é um politipo do sistema hexagonal com periodicidade de quatro vezes a dimensão $\mathrm{c}$ da wurtzita parental; wurtzita-15R é um politipo do sistema romboédrico com periodicidade de 15 vezes.

Apesar de politipos não serem considerados espécies minerais, os autores são aconselhados a consultar a CNMMN antes de introduzir novos nomes de politipos para minerais na literatura.

Interestratificações regulares Novos nomes podem ser dados a üiterestratificações regulares em que os tipos de camadas, suas proporções relativas, composições químicas e regularidade de interestratificação foram bem documentados.

Critérios detalhados que determinam se a interestratificação é suficientemente regular para garantir um nome de espécie são fornecidos por Bailey (1981). Porém, qualquer novo nome proposto deve ser submetido à CNMMN. Exemplo: o nome aliettita foi dado à interestratificação regular 1:1 de talco e esmectita trioctaédrica.

ESPÉCIMENS TIPO Quando um novo mineral é 
descrito, ou um mineral existente é redefinido, o autor deve ter o cuidado de definir sua designação tipo e assegurar-se que um espécimen tipo é conservado como material de referência permanente pelo menos por um museu importante ou por uma coleção mineralógica reconhecida nacionalmente.

TRATAMENTO DE UMA PROPOSTA DE NOVO MINERAL Quando o presidente da CNMMN recebe uma proposta de um novo mineral, está autorizado a escrever ao autor solicitando mais dados que considerar desejáveis ou apontar possíveis objeções ao mineral ou ao nome. Se o autor assim o desejar, o presidente é solicitado a submeter a proposta à CNMMN, mesmo que não concorde com a mesma. Nestes casos, o presidente informará suas razões quanto a inadequabilidade da proposta no item "Observações do Presidente". O resumo da proposta, redigido pelo presidente, é enviado por via aérea a cada membro da CNMMN, e aproximadamente 60 dias são concedidos pra o retorno das papeletas de votação.

É solicitado aos membros da CNMMN não apenas que votem, mas também que comentem em detalhe as propostas. O presidente é autorizado a suspender à votação de uma proposta para possibilitar a obtenção de mais informações ou solicitar uma segunda votação de uma proposta se, em sua opinião, comentários importantes feitos por alguns dos membros devam ser julgados pelos demais membros. Ao segundo voto é dado o mesmo prazo de votação (aproximadamente 60 dias), requerendo-se a mesma maioria que propostas originais (ver a seguir). Qualquer membro da CNMMN que se opuser a uma proposta poderá solicitar ao presidente que suspenda a votação ou convoque uma nova votação, mas a decisão é do presidente.

Resumos de propostas sobre minerais "de minério" podem ser enviados a membros da Comissão de Mineralogia de Minérios da IMÃ, a critério do presidente. Similarmente, o presidente pode submeter resumos de quaisquer propostas a outros especialistas para opiniões consultivas. Estes consultores não votam, mas seus comentários são considerados pelo presidente. Objeções importantes levantadas por quaisquer consultores são tratadas pelo presidente conforme especificado anteriormente.

Propostas .que tratam de minerais pertencentes a grupos de minerais para os quais subcomitês foram organizados pela CNMMN podem ser enviadas ao presidente do apropriado subcomitê para circulação entre seus membros, se o presidente da CNMMN julgar esta ação aconselhável. Os membros do subcomitê são convidados a emitir opiniões, e objeções sérias levantadas por eles são tratadas conforme especificado anteriormente.

Se duas ou mais propostas para o mesmo mineral novo são recebidas pelo presidente, a proposta recebida primeiramente no escritório do presidente terá prioridade.

Um novo mineral proposto será considerado aprovado se mais da metade $(1 / 2)$ dos membros da CNMMN votarem a proposta, e se mais de dois terços $(2 / 3)$ destes membros votarem "sim". Um nome proposto será considerado aprovado se mais de metade $(1 / 2)$ dos membros que votarem a proposta assinalarem "sim". No cálculo dos resultados da votação, uma abstenção é tratada como voto negativo. Após o final da votação de uma proposta, o presidente enviará os resultados aos membros da CNMMN e ao autor da proposta. Ele incluirá os comentários dos membros votantes, mas os votos dos membros não são revelados individualmente. $\mathrm{O}$ autor pode solicitar a reconsideração de votos contrários a qualquer tempo se novos dados ou novas interpretações significativas forem obtidas. Se um mineral for aprovado, mas não o nome, um novo nome deve ser solicitado pelo presidente quando este notificar o autor dos resultados da votação. Em casos de repetição de votação, a aprovação do mineral e do nome requererão a mesma maioria que na votação original.
Autores que descreveram novos minerais sem nome não tem quaisquer direitos de prioridade na denominação subseqüente de tais minerais. Quaisquer nomes propostos subseqüentemente terão de ser aprovados pela CNMMN, assim como os minerais para os quais os nomes são propostos.

A publicação de nomes não aprovados, ou nomes de minerais não aprovados não é perdoada. Minerais não aprovados para os quais descrições foram publicadas devem ser tratados como minerais sem nomes e seguir as cláusulas do parágrafo precedente.

REDEFINIÇÃO, DESCRÉDITO E REVALIDAÇÃO DE MINERAIS Sempre que possível, a redefinição ou descrédito de um mineral deve ser baseada no estudo do material tipo. Se um espécimen tipo existe e se a descrição original, mesmo imprecisa, representa razoável aproximação do material do espécimen, o mineral deve ser definido preferencialmente por referência ao material tipo que à descrição original. Isto significa que erros na descrição original não podem ser utilizados para desacreditar um mineral, a menos que a descrição original foi tão grosseiramente imprecisa que, nas palavras de Dana (1868), "o reconhecimento do mineral por meio dela é impossível". Se o material tipo não puder ser obtido para estudo, o investigador pode propor um neotipo à CNMMN, estabelecendo claramente que foram feitos esforços para conseguir o espécimen tipo original. Tanto a aceitação do neotipo quanto a aprovação da proposta dependem da CNMMN.

Se for demonstrado que um mineral é uma mistura e um de seus componentes é novo, o nome deverá usualmente ser transferido para esta nova fase; uma proposta para isto precisa também ser aprovada pela CNMMN antes da publicação.

Se os autores que originalmente propuseram um mineral que está sendo desacreditado ou redefinido estiverem vivos, o autor da proposta de descrédito ou redefinição deve escrever àqueles autores, solicitando seus comentários sobre a proposta; estes comentários devem acompanhar a submissão à CNMMN. O vice-presidente pode, também, escolher o contato independentemente com os autores que originalmente propuseram o nome.

Modificações menores na definição de um mineral em particular não necessitam ser levados à CNMMN, ao contrário de modificações substanciais: em geral, uma redefinição que requer aprovação da CNMMN é: a. uma que adiciona ou subtrai um ou mais componentes químicos essenciais à definição do mineral; b. propõe um novo limite composicional a um membro de uma série de solução sólida, ou c. propõe mudanças importantes na estrutura do mineral. Em caso de dúvida, a proposta de redefinição deve ser enviada ao vice-presidente da CNMMN para uma decisão.

Um nome de mineral pode ser desacreditado se for provado que o mineral é idêntico a outro que tenha prioridade, ou se o nome é enganoso. Todos estes casos necessitam ser submetidos ao vice-presidente da CNMMN para aprovação.

Exemplo: requer aprovação um caso similar àquele da johachidolita (Am. Mineral. 62:327), no qual se demonstrou que os elementos $\mathrm{H}$, Na e F não são essenciais ao mineral.

Exemplo: requer aprovação um caso similar àquele da sarcolita (Mineral. Mag. 48:107), no qual foi demonstrado que F é essencial ao mineral.

Exemplo: requer aprovação um caso similar àquele da hauchecornita (Mineral. Mag. 43:873), no qual foi demonstrada a ordenação de Bi, As, Sb e Te em duas posições estruturais, exigindo a redefinição do nome original e a introdução de três novos nomes de minerais para membros extremos.

Exemplo: requer aprovação um caso similar àquele de minerais do grupo do anfibóHo, no qual foram propostos limites composicionais para membros de séries de soluções sólidas (Am. Mineral. 63:1023).

Exemplo: não requer aprovação um caso similar àquele da 
pierrotita (Zeits. Kristaüogr. 165:209), no qual um átomo de $\mathrm{S}$ foi subtraído da fórmula, porque nenhum elemento essencial foi adicionado ou eliminado, tendo sido modificada somente sua proporção. Porém, se esta mudança houvesse sido acompanhada por mudança na simetria do mineral, então deveria ter sido requerida aprovação.

Exemplo: requer aprovação um caso similar àquele da onoratoíta, originalmente descrita como triclmica, mas posteriormente demonstrada ser monocünica (Acta Crystallogr. C40:1506)..

Exemplo: requer aprovação um caso similar àquele da mohsita, que foi desacreditada (Can. Mineral. 17:635), porque um novo exame do material tipo mostrou que ela era essencialmente similar à crichtonita, que teve prioridade sobre mohsita. Exemplo: um caso similar àquele da ferroschaflerita, que foi desacreditada pois o re-exame do material tipo mostrou que ela não era o análogo de $\mathrm{Fe}$ da schaüerita e que ela não apresentava a estrutura da schaflerita (Mineral. Mag. 48:271).

Um nome desacreditado não deve ser usado na literatura, exceto para registrar seu descrédito. Porém, se houver evidência de que um mineral previamente desacreditado é válido, uma proposta para revalidar o nome deve ser submetida à CNMMN para reconsideração.

O tratamento de propostas para redefinição, descrédito ou revalidação é similar àquele para introduzir um novo nome de mineral, e a maioria de mais de dois terços é requerida para aprovar tais propostas.

Uma lista de nomes de minerais desacreditados pela CNMMN é fornecido no apêndice 1 .

SELEÇÃO DE UM NOME DE MINERAL Modificadores Um modificador é normalmente utilizado para indicar uma modificação composicional, e.g. manganotantalita com $\mathrm{Fe}$ (II), em que manganotantalita é o nome do mineral e "com Fe (II)" é o modificador que indica a presença de $\mathrm{Fe}(\mathrm{II})$. Um modificador não é considerado parte integrante do nome do mineral; apenas dá informações adicionais sobre sua composição química. Deve ser, portanto, ignorado na preparação de índices alfabéticos. Em determinados artigos, um modificador é dado na forma de um prefixo com o símbolo do elemento químico ligado por hffen, e.g. Li-tosudita, ao invés de tosudita com $\mathrm{Li}$ ou tosudita rica em $\mathrm{Li}$. Este uso é incorreto e deve ser evitado, assim como também a substituição de parte integrante do nome do mineral por símbolos químicos, e.g. manganotantalita nunca deve ser substituído por Mn-tantalita.

Nomes de grupos e de variedades Um nome de mineral pode ser usado para um grupo de minerais, e.g. mica, ou para uma espécie mineral, e.g. muscovita. Às vezes o nome de uma espécie é também usado como um nome de grupo, e.g. a espécie pirita é um membro do grupo da pinta. No passado, variedades de minerais recebiam nomes especiais, e.g. kunzita (uma variedade de espodumênio), mas esta prática não é aprovada.

Seleção de nomes Nomear um novo mineral é prerrogativa e responsabilidade do autor principal da proposta submetida à CNMMN para aprovação, mas aconselha-se que a escolha de um novo nome siga as seguintes diretrizes:

$\mathrm{O}$ nome deve ser suficientemente diferente dos nomes já existentes para evitar confusão, tanto na língua materna do autor como em outras. Na nomenclatura existente de minerais já há um número de exemplos de nomes desafortunados que são facilmente confundidos; nomes como celadonita e caledo- nita, ou mallardita e malladrita podem ser grafadas erroneamente; nomes como rhodesita, rhodizita e rhodusita são foneticamente muito similares. A introdução de novos nomes que possam criar problemas semelhantes deve ser evitada.

-Se o novo mineral é relacionado a um já existente, é desejável que esta relação seja indicada pelo novo nome, e.g. clinoenstatita para o dimorfo monoclmico de enstatita, ou magnesiocopiapita para o análogo de $\mathrm{Mg}$ de copiapita. Tal nome deve consistir de apenas uma palavra (e.g. magnesiocopiapita, não magnésio copiapita).

Esforços devem ser feitos no sentido de se escolher um nome simples ao invés de um excessivamente complicado que possa ser difícil de ler ou pronunciar.

$\mathrm{O}$ uso de nomes muito longos deve ser evitado, pois podem causar dificuldades na pronúncia, nas tabulaçôes e em bancos de dados de computadores.

$\mathrm{O}$ nome de um mineral com elementos terras-raras essenciais (ou o elemento quimicamente relacionado) deve ter um sufixo indicando o elemento terra-rara dominante, e.g. bastnãsita-(Ce), e se for descoberto um novo mineral com a mesma estrutura e de composição análoga, mas com um elemento terra-rara dominante diferente, ele deve receber um nome análogo ao do mineral já existente, e.g. bastnâsita-(Y). Um sufixo desse tipo é conhecido por "modificador de Levinson", em referência ao autor que introduziu tal procedimento (Levinson 1966). A CNMMN recentemente decidiu que os nomes de todos os minerais contendo elementos terras-raras essenciais, incluindo aqueles introduzidos na literatura antes da publicação do trabalho de Levinson (1966) devem ser modificados para o formato aprovado. Uma lista destes nomes de minerais é fornecido no apêndice 2.

Em poucos casos, um procedimento similar tem sido usado para minerais que não contém elementos terras-raras, e que podem conter diferentes elemento» substituindo-se em uma ou mais posições estruturais, e.g. jahnsita-(CaMnMg). Em geral, este tipo de nomenclatura é aceitável nos casos em que apenas um elemento é usado como sufixo, mas sufixos consistindo de múltiplos elementos são condicionalmente aceitáveis em casos cuja estrutura é complexa e o uso de tais sufixos simplifica a nomenclatura.

Sufixos podem também ser usados para indicar relações cristalográficas. Este uso já foi citado no caso de politipos, mas tem sido recentemente estendido a minerais que não são politipos quando rigorosamente aplicada a definição, e.g. hilgardita-37c (Ghose 1985).

Relações com outros minerais podem também ser indicadas pelo uso de prefixos, e.g. clinoenstatita, o dimorfo monoclmico da enstatita; ou magnesiocromita, o análogo de Mg da cromita. $\mathrm{O}$ uso de um hífen para distinguir o prefixo do nome raiz é desencorajado, mas quando um nome sem hífen tornar-se desastroso e o hífen ajudar a decifrá-lo, deve ser usado, e.g. hidroxiI-bastnãsita-(Ce).

Quando prefixos químicos são usados, os derivados do latim devem ser preferidos sempre que possível, e.g. "ferro" no lugar de "iron", "plumbo" no lugar de "blei" etc (Hey \& Gottardi 1980).

O prefixo é parte integrante do nome do mineral e deve geralmente ser tratado como tal na preparação de índices alfabéticos; porém, uma exceção pode ser feita no caso de símbolos usados como prefixos com letras gregas ou em sua grafia latina equivalente. Uma recente decisão da CNMMN permite seu posicionamento após o nome principal; e.g. $\beta$-roselita pode ser escrito como roselita- $\beta$ ou roselita-beta.

Se o mineral for denominado a partir do nome de pessoa

Nota dos tradutores-, no original deste trabalho, em inglês, é sugerido o uso de prefixos terminados em oan para indicar fons com menor Valencia e ian para fons de maior Valencia, e.g. "ferroan manganotantalite" [ = manganotantalita com Fe(II)] • Este sistema já havia sido discutido anteriormente por Schaller (1930) e por Hey \& Gottardi (1980). Tais modificadores, entretanto, não se adequara à língua portuguesa. Sugere-se aqui o uso do símbolo do elemento qutoico e sua Valencia (no caso de elementos que podem apresentar normalmente mais de um estado de Valencia), precedido de "com" ou "rico em". 
que contenha um espaço letra maiúscula, o nome deve ser modificado a fim de eliminá-los, e.g. mcnearita, não mcNearita, joesmithita, não joe smithita. De outra forma, a grafia original do nome da pessoa dever ser mantida. Se o mineral é denominado a partir do nome de pessoa viva, o autor deve obter a permissão daquela antes da submissão da proposta à CNMMN. Quando decidir denominar um mineral em homenagem a uma pessoa, é bom relembrar o preceito de Dana (1844): "Deve ser lembrado que o uso de nome de pessoas eminentes em outras ciências, ou de pessoas alheias a todas as ciências, está totalmente em desacordo com o bom uso e propriedade; além disso, a tentativa de bajular os que se sobressaem na política é degradante para a ciência e nunca será suficientemente rechaçada".

Apesar da CNMMN não ter estabelecido uma política quanto ao uso de nomes pessoais compostos, alguns membros da comissão colocaram-se fortemente em seu desfavor, particularmente quando se tornam incômodos ou cacofônicos, ou quando modificam desnessariamente os verdadeiros nomes do indivíduo que está supostamente sendo, homenageado.

Se a denominação do mineral for feita a partir de uma ocorrência geográfica, deve-se tomar cuidado em assegurar que a grafia esteja de acordo com aquela em uso na localidade, e não deve ser baseado em traduções.

Nomes de minerais propostos em línguas que usam outros caracteres que aqueles do alfabeto latino devem ser transliterados para o alfabeto latino conforme o sistema reinante no país de origem. No caso de nomes cirflicos, transliterações seguem o Sistema Padrão Britânico (British Standard System), que foi adotado pela CNMMN.

As marcas diacríticas devem ser mantidas quando possível, mas reconhece-se que nem todos os estabelecimentos de impressão têm as faculdades necessárias para imprimir todos os tipos de marcas diacríticas; em tais casos, estas podem ser omitidas.

A reutilização de nomes desacreditados ou obsoletos para um mineral novo ou redefinido deve ser desencorajada, exceto quando o novo mineral é um componente de uma mistura originalmente descrita como mineral único; em tal caso, o nome original pode ser transferido à nova fase. A reutilização de um nome desacreditado pode também ser permitida se existir uma boa razão pela qual esse nome é particularmente apropriado para o mineral em questão, e também se o nome desacreditado ou obsoleto não tem aparecido na literatura ativa (exceto para o artigo de sua desacreditação) por cinquenta anos. Uma proposta para reutilizar um nome obsoleto necessita ser acompanhada ou precedida por uma proposta para desacreditar o nome obsoleto. Se a CNMMN não aprovar a proposta para reutilizar o nome desacreditado, o autor da proposta não tem nenhuma prioridade para o uso do nome desacreditado, apesar de ele estar livre para propor novamente o nome futuramente.

A reutilização de um nome obsoleto ou desacreditado não será permitida se o nome foi utilizado fora do campo da mineralogia (e.g., em petrografia, metalurgia, paleontologia etc), ou para indicar dois ou mais minerais.

Se uma substância artificial recebeu um nome, e o mineral correspondente àquela substância é posteriormente descoberto, o nome dado à substância artificial não necessariamente terá de ser aplicado ao mineral.

PUBLICAÇÃO DE DESCRIÇÕES DE MINERAIS APROVADOS Autores de propostas aprovadas devem publicar as descrições dos minerais tratados nestas propostas no prazo de dois anos a contar da notificação da aprovação pelo presidente ou vice-presidente. Se descrições de novos minerais, descréditos, redefinições ou revalidações não forem publicadas no prazo previsto, estas não serão mais consideradas como aprovadas. Quaisquer prorrogações daquela data limite precisam ser aprovadas pelo presidente ou vice-presidente, conforme o caso.

RECOMENDAÇÕES AOS EDITORES Editores de revistas de mineralogia e geologia estarão prestando um grande serviço às geociências se cooperarem plenamente com a CNMMN. Todos os aspectos da nomenclatura em manuscritos deverão ser avaliados de acordo com as instruções dadas aqui; deve-se assegurar que os autores submeteram todos os itens relativos à nomenclatura mineral à $\mathrm{CNMMN}$, e que suas propostas foram aprovadas. A menos que tenham prova definitiva da aprovação, os editores devem consultar seus representantes nacionais ou membros executivos da CNMMN. Os editores devem ser particularmente cautelosos quanto à aceitação final de artigos contendo frases como "foi submetido" ou "será submetido" à CNMMN. A aceitação de tais artigos deve ser adiada até que se produzam evidências de que a nomenclatura foi aprovada pela CNMMN.

No caso de novos minerais, os editores devem insistir na evidência de que um espécimen tipo do novo mineral foi alojado em pelo menos um museu importante ou em uma coleção mineralógica reconhecida nacionalmente.

Far-se-á juz a todas as revistas que publicam artigos mineralógicos, se estas incluírem o seguinte texto em suas instruções aos autores:

"Este periódico segue as regras da Comissão de Novos Minerais e Nomes de Minerais da Associação Mineralógica Internacional em todos os itens relacionados a nomes de minerais e nomenclatura mineralógica".

Agradecimentos Representantes nacionais da CNMMN contribuíram substancialmente para este documento com seus comentários e sugestões durante sua preparação. Os autores são também gratos pelas sugestões proveitosas efetuadas pelo Dr. P. Bayliss, editor do JCPDS Mineral Powder Diffraction Füe.

\section{REFERÊNCIAS BIBLIOGRÁFICAS}

BAILEY, S.W. 1981. Nomenclature for regular intentratifications. CanMineral., 19:651-655.

DANA, J.D. 1844. A system of mineralogy. New York, Wiley and Sons. (4? edição)

DANA, J.D. 1868. A system of mineralogy. New York, Wiley and Sons. (5- edição)

DONNAY, G. \& FLEISCHER, M. 1970. Suggested outline for new mineral descriptions. Am. Mineral., 55:1017-1019.

EMBREY, P.G. \& HEY, M.H. 1970. "Type" specimens in rmnenlogy. Mineral. Rec., 1:102-104.

FLEISCHER, M. 1970. Procedure of the International Mineralogical Association Commission on New Minerals and Mineral Names. Am. Mineral., 55:1016-1017.

GHOSE, S. 1985. A new nomenclature for the borate minerals in the hilgardite $\left(\mathrm{Ca}_{2} \mathrm{~B}_{5} \mathrm{OgCl}-\mathrm{H}_{2} \mathrm{O}\right)$-tyretskite $\left(\mathrm{Ca}_{2} \mathrm{~B}_{5} \mathrm{O}_{9} \mathrm{H}-\mathrm{H}_{2} \mathrm{O}\right)$ group. Am. Mineral., 70:636-637.

GUINIER, A., et al. 1984. Nomenclature of polytype structures. Report of the International Union of Crystallography Ad-Hoc Committee on the Nomenclature of Disordered, Modulated and Polytype Structures. Acta CrystaUog., A4fe399-404

Revista Brasileira de Geodêndas, Volume 20,1990
HEY, M.H. \& GOTT ARDI, C. 1980. On the une of names, prefixes and suffixes and adjectival modifiers in the mineralogical nomenclature. Am. Mineral., 65:223-224.

LEVINSON, A.A. 1966. A system of nomenclatures for rare-earth minerals. Am. Mineral., 51:152-158.

MANDARINO, J.A.; NICKEL, E.H.; CESBRON, F. 1984. Rules of procedure of the Comission on New Minerals and Mineral Names, International Mineralogical Association. Am. Mineral., 59:563-564; Can. Mineral., 22:367-368; Mineral. Mag., 48:567-568

RAMSDELL, L.S. 1947. Studies on silicon carbide. Am. Mineral., 32:64-82

SCHALLER, W.T. 1930. Adjectival ending of chemical elements used as modifiers to mineral names. Am. Mineral., 15:567-574.

MANUSCRITO P009 Recebido em 20 de julho de 1990 
Apêndice l - Nomes de minerais desacreditados pela CNMMN (não devem figurar em publicações) e aprovados (se existentes, podem ser usados no lugar dos desacreditados).

\begin{tabular}{|c|c|}
\hline NOME DESACREDITADO & NOME APROVADO \\
\hline abkhazita & tremolita \\
\hline abriachanita & riebeckita \\
\hline absita & brannerita \\
\hline abukumalita & britolita-(Y) \\
\hline achrematita & mistura \\
\hline acromaita & hornblenda \\
\hline actinoto & actinolita \\
\hline adelfolita & samarskita-(Y) \\
\hline $\begin{array}{l}\text { alascaíta } \\
\text { alazanita }\end{array}$ & mistura \\
\hline albrittonita & \\
\hline alcalifemaghastingsita & hastingsita com $\mathrm{Na}, \mathrm{K}$ e $\mathrm{Mg}$ \\
\hline $\begin{array}{l}\text { alcali-ferro-hastingsita } \\
\text { alcali-hastingsita }\end{array}$ & hastingsita com $\mathrm{Na}$ e K \\
\hline aldzhanita & 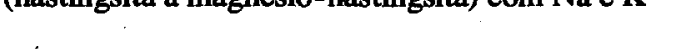 \\
\hline alfa-catapleita & gaidonnayita \\
\hline allcharita & goethita \\
\hline allemontita & estibarsênio \\
\hline allevardita & rectorita \\
\hline almbosita & \\
\hline almerifta & natroalunita \\
\hline alopaládio & estibiopaladinita \\
\hline altmarkita & \\
\hline aluminobetafita & \\
\hline aluminobritolita . & \\
\hline $\begin{array}{l}\text { alumocobaltomelana } \\
\text { alumoferroascharita }\end{array}$ & mistura \\
\hline ameletita & nefelina e mistura \\
\hline amiantinita & asbesto \\
\hline amianto & asbesto \\
\hline amiantoide & asbesto \\
\hline amosita & grunerita asbestiforme ou antofilita antes de 1948 \\
\hline ampangabeíta & samarskita-(Y) \\
\hline analcita & analcima \\
\hline anarakita & \\
\hline anauxita & caulinita \\
\hline anfibólio-antofilita & cummingtonita \\
\hline anfibolita & hornblenda \\
\hline anoforita & magnésio-arfvedsonita com Ti(IV) e Ca \\
\hline antiglaucofânio & glaucofânio ou crossita \\
\hline antófilina & antofilita \\
\hline antofilita rayonnée & antofilita \\
\hline antogrammatita & antofilita \\
\hline atogrammita & antofilita \\
\hline antolita & antofilita e cummingtonita \\
\hline arfwedsonita & arfvedsonita \\
\hline argentocuproaurita & \\
\hline arsenato-belovita & talmessita \\
\hline arsenodialytita & \\
\hline asbeferrita & asbesto \\
\hline asbestinita & asbesto \\
\hline asbest6ide & asbesto \\
\hline ascarita & szajbelyíta \\
\hline ashtonita & mordenita com Sr \\
\hline astochita & richterita com Mn(II) \\
\hline astorita & richterita \\
\hline astrakanita & blödita \\
\hline astrolita & muscovita \\
\hline $\begin{array}{l}\text { aurocuprita } \\
\text { azor-pirrita }\end{array}$ & \\
\hline $\begin{array}{l}\text { azor-purnta } \\
\text { bababudanita }\end{array}$ & magnésio-riebeckita \\
\hline badenita & mistura \\
\hline balavinskita & . \\
\hline barcenita & cinábrio + romeíta \\
\hline
\end{tabular}

\section{REFERÊNCIA}

Am. Min. 63 (1978), 1023

Am. Min. 63 (1978), 1023

Am. Min. 48 (1963), 1419

Am. Min. 51 (1966), 152

Am. Min. $62(1977), 170$

Am. Min. 63 (1978), 1023

Am. Min. 63 (1978), 1023

Am. Min. 51 (1966), 1553

Am. Min. 58 (1973), 349

Min. Mag. 43 (1980), 1055

Am. Min. 67 (1982), 156

Am. Min. 63 (1978), 1023

Am. Min. 63 (1978), 1023

Am. Min. 63 (1978), 1023

Min. Mag. 43 (1980), 1055

Can. Min. 16 (1978), 195

Bull. Min. 92 (1969), 99

Min. Mag. 46 (1982), 513

Am. Min. 49 (1964), 446

este artigo

Min. Mag. 33 (1962), 353

Am. Min. 63 (1978), 796

Min. Mag. 43 (1980), 1055

Min. Mag. 36 (1967), 133

Min. Mag. 36 (1967), 133

Min. Mag. 33 (1962), 261

Am. Min. 49 (1964), 1501

Min. Mag. 36 (1968), 438

Am. Min. 63 (1978), 1023

Am. Min. 63 (1978), 1023

An. Min. 63 (1978), 1023

Am. Min. 63 (1978), 1023

Min. Mag. 33 (1962), 262

Min. Mag. 43 (1980), 1053

Min. Mag. 43 (1980), 1053

Am. Min. 54 (1969), 206

Am. Min. 63 (1978), 1023

Am. Min. 63 (1978), 1023

Am. Min. 63 (1978), 1023

Am. Min. 63 (1978), 1023

Am. Min. 63 (1978), 1023

Am. Min. 63 (1978), 1023

Am. Min. 63 (1978), 1023

Am. Min. 63 (1978), 1023

Am. Min. 63 (1978), 1023

Am. Min. 63 (1978), 1023

Min. Mag. 43 (1980), 1055

este artigo

Bull. Min. 97 (1974), 520

Am. Min. 63 (1978), 1023

Am. Min. 63 (1978), 1023

Am. Min. 63 (1978), 1023

este artigo

Min. Mag. 38(1971), 383

Am. Min. 63 (1978), 1023

Am. Min. 63 (1978), 1023

este artigo

Am. Min. 57 (1972), 993

Min. Mag. 43 (1980), 1055

Am. Min. 62 (1977), 403

Am. Min. 63 (1978), 1023

Min. Mag. 47 (1983), 411

Min. Mag. 38 (1971), 103

Can. Min. 24 (1986), 591

Min. Mag. 38 (1971), 103 
bário-farmacossiderita
barkevicita

barkevikita

barsanovita

basaltina

basiliíta

bedenita

belovita (de Nefedov)

bergamaschita

bergamaskita

bergflachs

bergfleisch

berghaar

berghaut

bergholz

bergkork

bergpapier

bergwolle

berflio-sodalita

berilossodalita

beta-alumoidrocalcita

beta-brocenita

beta-lomonosovita

bialita

bidalotita

bisbeefta

bissolita

biteplapaladita

biteplatinita

blanchardita

blenda

bloedita

blomstrandita

boleslavita

boodtita

borgniezita

borvickyita

breadalbanita

brocenita

bromirita

brostenita

buryktalskita

cacoclasita

calafatita

calamina

calamita

cálcio-hilgardita-2M(Cc)

cálcio-hilgardita-3Tc

cálcio-larsenita

cálcio-rinkita

cálcio-samarskita

cálcio-tantalita

calcolamprita

calcolita

carfossiderita

carintina

carnevallita

carystina

castaingita

cataforita

celestita

cerargirita

cerfosforhuttonita

cerolita

ceruranopirocloro

challantita

chalybita

chengbolita hornblenda pargasítica com Fe(II) ou ferro-hornblenda pargasítica

hornblenda pargasítica com $\mathrm{Fe}(\mathrm{II})$ ou ferro-hornblenda pargasítica

eudialita

oxi-hornblenda + augita

hausmannita + feitknechtita

hornblenda actinolftica com Fe(III)

talmessita

hastingsita

hastingsita

asbesto

asbesto

asbesto

asbesto

asbesto

asbesto

asbesto

asbesto

tugtupita

turgtupita

wavellita

gedrita

crisocola

asbesto

merenskyita

monchefta

brochantita

esfalerita

blödita

uranopirocloro

heterogenita

anfibblio de $\mathrm{Na}$

hornblenda

fergusonita-beta-(Ce)

bromargirita

birnessita + todorokita

mistura

alunita

hemimorfita

tremolita

esperita

götzenita

itropirocloro com U(VI)

mistura

pirocloro impuro

torbernita

hidrônio-jarosita

hornblenda

asbesto

catoforita

celestina

clorargirita

serpentina + stevensita

pirocloro com Ce(IV)

ferricopiapita

siderita

monchefta
Min. Mag. 38 (1971), 103

Am. Min. 63 (1978), 1023

Am. Min. 63 (1978), 1023

Am. Min. 54 (1969), 1499

Am. Min. 63 (1978), 1023

Am. Min. 58 (1973), 562

Am. Min. 63 (1978), 1023 este artigo

Am. Min. 63 (1978), 1023

Am. Min. 63 (1978), 1023

Am. Min. 63 (1978), 1023

Am. Min. 63 (1978), 1023

Am. Min. 63 (1978), 1023

Am. Min. 63 (1978), 1023

Am. Min. 63 (1978), 1023

Am. Min. 63 (1978), 1023

Am. Min. 63 (1978), 1023

Am. Min. 63 (1978), 1023

Am. Min. 48 (1963), 1178

Am. Min. 46 (1961), 241

Min. Mag. 36 (1967), 133

Min. Mag. 43 (1980), 1055

Min. Mag. 36 (1967), 133

Min. Mag. 37 (1969), 123

Am. Min. 63 (1978), 1023

Min. Mag. 43 (1980), 1054

Am. Min. 63 (1978), 1023

este artigo

este artigo

Am. Min. 58 (1973), 562

Min. Mag. 43 (1980), 1053

Min. Mag. 33 (1962), 263

Am. Min. 62 (1977), 403

Min. Mag. 36 (1967), 133

Min. Mag. 33 (1962), 253

Am. Min. 63 (1978), 1023 este artigo

Am. Min. 63 (1978), 1023

Min. Mag. 43 (1980), 1055

Min. Mag. 43 (1980), 1053

Min. Abst. 74-3408

Min. Mag. 33 (1962), 261

Am. Min. 52 (1967), 929

Am. Min. 48 (1963), 1184

Min. Mag. 43 (1980), 1053

Am. Min. 63 (1978), 1023

Min. Mag. 33 (1962), 261

Min. Mag. 33 (1962), 261

Am. Min. 50 (1965), 1170

Min. Mag. 33 (1962), 262

Am. Min. 62 (1977), 403

Min. Mag. 38 (1972), 765

Am. Min. 62 (1977), 403

Min. Mag. 43 (1980), 1053

este artigo

Am. Min. 63 (1978), 1023

Min. Mag. 43 (1980), 1055

Am. Min. 63 (1978), 1023

Min. Mag. 36 (1967), 133

Am. Min. 63 (1978) 1023

Min. Mag. 43 (1980), 1053

Min. Mag. 43 (1980), 1053

Min. Mag. 36 (1968), 1144

Am. Min. 50 (1965), 2111

Am. Min. 62 (1977), 403

Can. Min. 23 (1985), 53

Min. Mag. 43 (1980), 1053

Min. Mag. 43 (1980), 1055 


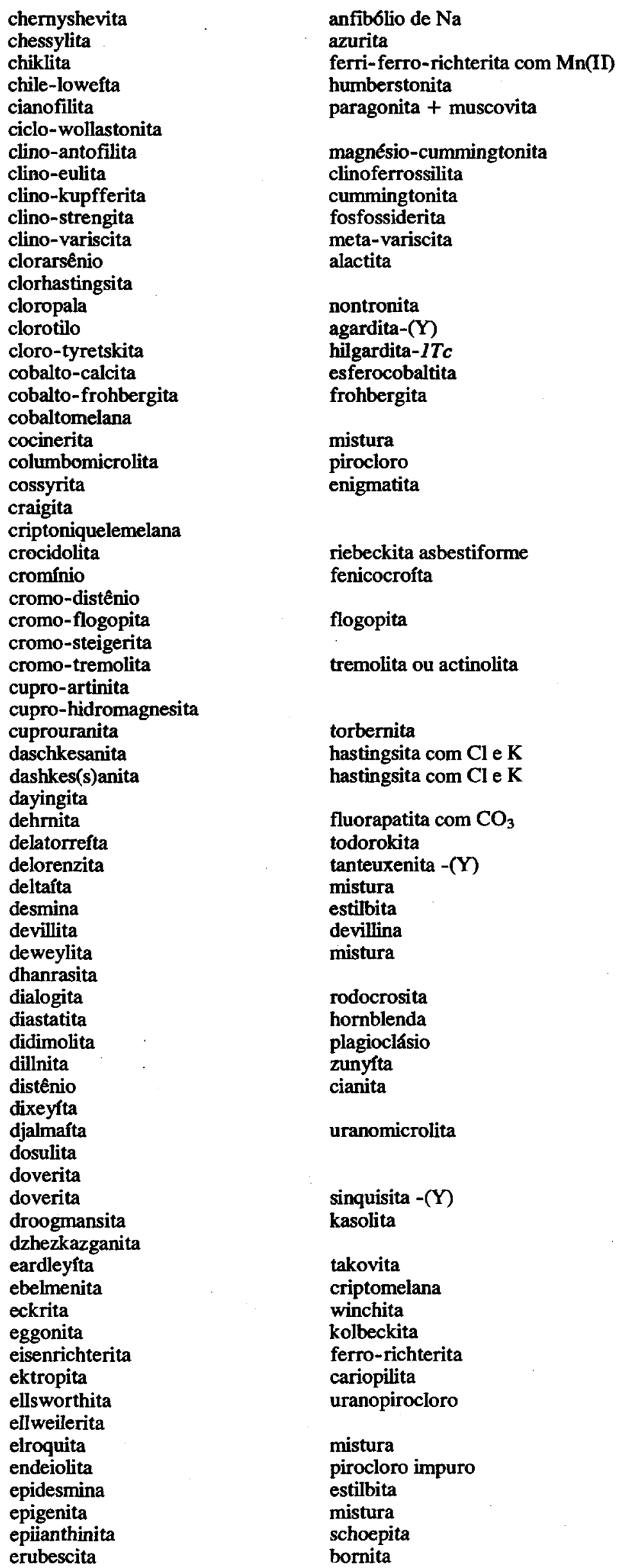

Am. Min. 63 (1978), 1023

Min. Mag. 43 (1980), 1053

Am. Min. 63 (1978), 1023

Min. Abst. 70-1634

Am. Min. 58 (1973), 807

Min. Mag. 43 (1980), 1055

Am. Min. 63 (1978), 1023

este artigo

Am. Min. 63 (1978); 1023

Min. Mag. 43 (1980), 1053

Min. Mag. 43 (1980), 1053

Am. Min. 58 (1973), 562

Min. Mag. 38 (1971), 103

Min. Mag. 43 (1980), 1053

Min. Mag. 37 (1970), 954

Am. Min. 70 (1985), 636

Min. Mag. 43 (1980), 1053

este artigo

Min. Mag. 33 (1962), 261

Am. Min. 52 (1967), 1214

Am. Min. 62 (1977), 403

Am. Min. 49 (1964), 821

Min. Mag. 43 (1980), 1055

Min. Mag. 33 (1962), 261

Am. Min. 63 (1978), 1023

Bull. Min. 95 (1972), 427

Min. Mag. 38 (1971), 103

Min. Mag. 43 (1980), 1055

Min. Mag. 36 (1967), 133

Am. Min. 63 (1978), 1023

Am. Min. 67 (1982), 156

Am. Min. 67 (1982), 156

Min. Mag. 43 (1980), 1053

Am. Min. 63 (1978), 1023

Am. Min. 63 (1978), 1023

Min. Mag. 43 (1980), 1055

Min. Mag. 42 (1978), 282

Min. Mag. 33 (1962), 262

Min. Mag. 33 (1962), 262

Min. Mag. 33 (1962), 262

Min. Mag. 43 (1980), 1053

Min. Mag. 43 (1980), 1053

Am. Min. 47 (1962), 811

Min. Mag. 38 (1971), 103

Min. Mag. 43 (1980), 1053

Am. Min. 63 (1978), 1023

Am. Min. 50 (1965), 2111

Am. Min. 46 (1961), 1519 este artigo

Min. Mag. 33 (1962), 261

Am. Min. 62 (1977), 403

Min. Mag. 43 (1980), 1055

Min. Mag. 33 (1962), 261

Am. Min. 51 (1966), 152

Bull. Min. 101 (1978), 56

Min. Mag. 36 (1967), 133

Am. Min. 62 (1977), 458

Min. Mag. 46 (1982), 513

Am. Min. 63 (1978), 1023

este artigo

Am. Min. 63 (1978), 1023

Am. Min. 49 (1964), 446

Am. Min. 62 (1977), 403

Min. Mag. 33 (1962), 261

Am. Min. 48 (1963), 1421

Am. Min. 62 (1977), 403

Am. Min. 53 (1968), 1066

Min. Mag. 47 (1983), 411

Min. Mag. 33 (1962), 262

Min. Mag. 43 (1980), 1053 


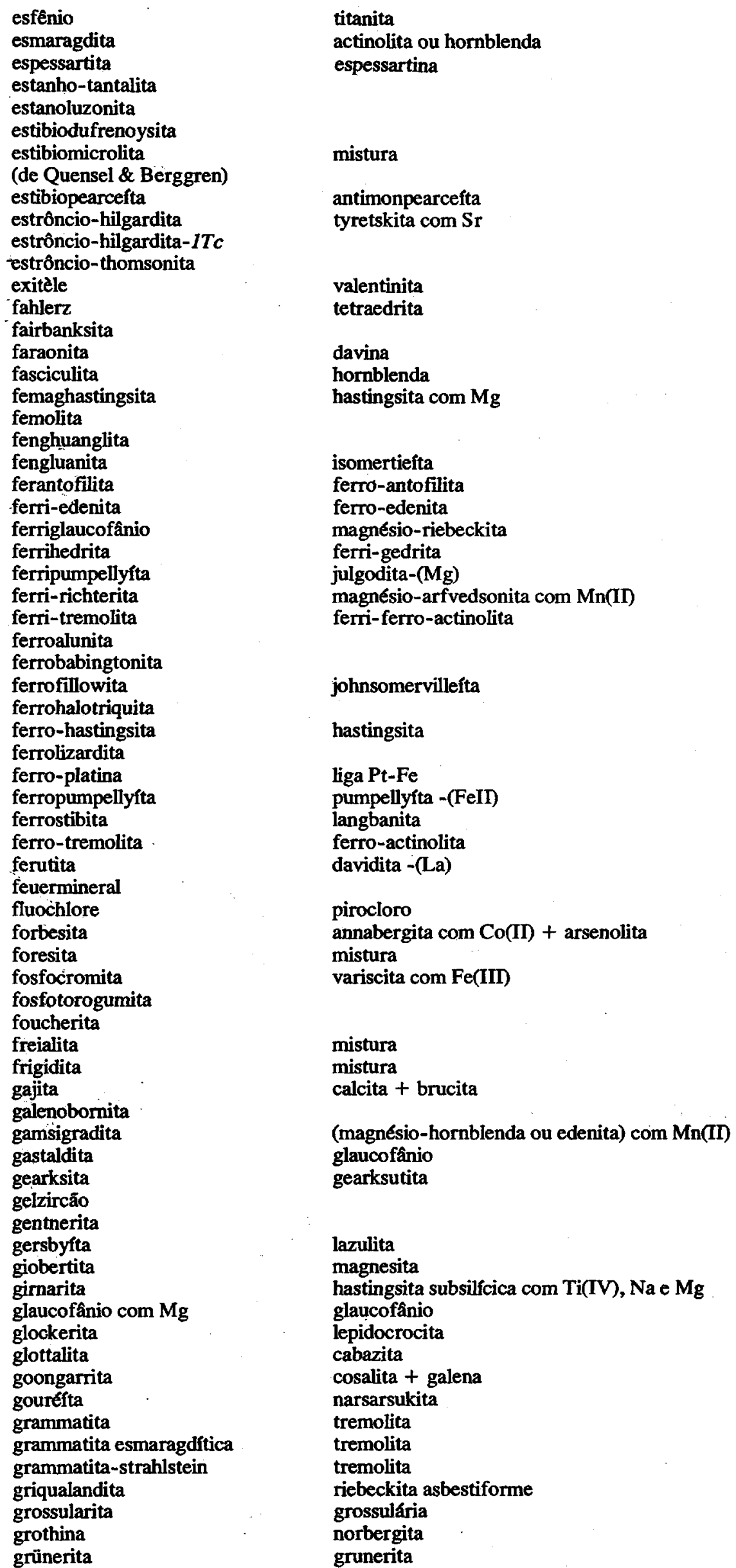

Min. Mag. 46 (1982), 513

Am. Min. 63 (1978), 1023

Mig. Mag. 43 (1980), 1053

Min. Mag. 36 (1967), 133

Min. Mag. 36 (1967), 133

Min. Mag. 38 (1971), 103

Am. Min. 62 (1977), 403

este artigo

Min. Mag. 46 (1982), 514

Min. Mag. 33 (1962), 261

Min. Mag. 36 (1988), 1144

Min. Mag. 43 (1980), 1053

Min. Mag. 43 (1980), 1053

Min. Mag. 36 (1968), 1144

Min. Mag. 43 (1980), 1055

Am. Min. 63 (1978), 1023

Am. Min. 63 (1978), 1023

Min. Mag. 36 (1967), 133

Min. Mag. 33 (1962), 261

Am. Min. 65 (1980), 408

Am. Min. 63 (1978), 1023

Am. Min. 63 (1978), 1023

Am. Min. 63 (1978), 1023

Am. Min. 63 (1978), 1023

Can. Min. 12 (1973), 219

Am. Min. 63 (1978), 1023

Am. Min. 63 (1978), 1023

Min. Mag. 36 (1968), 1144

Min. Mag. 38 (1971), 103

este artigo

Min. Mag. 43 (1980), 1055

Am. Min. 63 (1978), 1023

Min. Mag. 36 (1968), 1144

Can. Min. 13 (1975), 117

Can. Min. 12 (1973), 219

Am. Min. 53 (1968), 1779

Am. Min. 63 (1978), 1023

Am. Min. 49 (1964), 447

Min. Mag. 43 (1980), 1055

Am. Min. $62(1977), 403$

Can. Min. 14 (1976), 414

Min. Mag. 33 (1962), 262

Am. Min. 48 (1963), 1421

Min. Mag. 38 (1971), 103

este artigo

Am. Min. 70 (1985), 1059

Min. Mag. 43 (1979), 99

Min. Mag. 33 (1962), 262

Min. Mag. 36 (1967), 133

Am. Min. 63 (1978), 1023

Am. Min. 63 (1978), 1023

Min. Mag. 33 (1962), 262

Min. Mag. 36 (1967), 133

Min. Mag. 36 (1968), 1144

Am. Min. 49 (1964), 1778

Min. Mag. 43 (1980), 1053

Am. Min. 63 (1978), 1023

Am. Min. 63 (1978), 1023

Am. Min. 62 (1977), 599

Min. Mag. 33 (1962), 262

Am. Min. 49 (1964), 1501

Am. Min. 46 (1961), 1520

Am. Min. 63 (1978), 1023

Am. Min. 63 (1978), 1023

Am. Min. 63 (1978), 1023

Am. Min. 63 (1978), 1023

Min. Mag. 43 (1980), 1053

Min. Rec. 12 (1981), 377

Am. Min. 63 (1978), 1023 
grünlingita

guanglinita

gutsevichita

haddamita

haematita

hanlefta

hatchettolita

heikkolita

heikolita

henwoodita

herrengrundita

heterotipo

heubachita

hexabolita

hexagonita

hexastibiopaladita

hidrargilita

hidroamesita

hidrocalcita (de Marschner)

hidrocastorita

hidrocatapleifta

hidrocerita

hidrocianita

hidrocloro

hidrohalloysita

hidrokassita

hidromolisita

hidronaujakasita

hidropirocloro

hidrorrinkita

hidrossericita

hidrossodalita

hidrougrandita

hidroxil-ascharita

hidroxil-szajbelyfta

hillängsita

hoeferita

hoepfnerita

hogveitita

holzasbest

hongquifta

hormites

hornblenda basáltica

hornblenda labrador

hudsonita

idocrásio

igalikita

igdlóta

imerinita

imgreïta

iodirita

iron-antofilita

iron-hormblenda

iron-richterita

isabellita

ishiganefta

iso-platina-cobre

isowolframita

itrohatchettolitá

itromicrolita

jenkinsita

jezekita

jiningita

johnstonotita

juddita

julgoldita joseíta A/bismutinita

microlita

hematita

uvarovita

uranopirocloro

crossita

crossita

turquesa

devillina

anfibólio + piroxênio

heterogenita com Ni(III)

oxi-hornblenda

tremolita com Mn(II)

sudburyíta

gibbsita

mistura

calcocianita

pirocioro

pirocloro alterado

dannemorita
chapmanita
tremolita
thalenita -(Y)
asbesto

asbesto

uma oxi-hornblenda, freqüentemente magnésio-ferri-hastingsita, ou magnésiohastingsita com Fe(III) e Ti(TV), ou ferri-hastingsita com $\mathrm{Mg}$, ou hastingsita com $\mathrm{Mg}, \mathrm{Fe}$ (III) e Ti(IV)

ortopiroxênio

hastingsita

vesuvianita

analcima + muscovita

lueshita

magnésio-arfvedsonita

iodargirita

ferro-antofilita

oxi-ferro-hornblenda com Mn(II), $\mathrm{K}$ e Fe(III)

ferro-richterita

richterita

criptomelana + bimessita

itropirocloro $-(Y)$

antigorita com $\mathrm{Fe}(\mathrm{II})$

morinita

espessartita

magnésio-arfvedsonita com $\mathrm{Mn}$ (II)

julgodita -(FeII)
Am. Min. 67 (1982), 855

Min. Mag. 43 (1980), 1055

Min. Mag. 33 (1962), 261

Am. Min. 62 (1977), 403

Mig. Mag. 43 (1980), 1053

Min. Mag. 33 (1963), 508

Am. Min. 62 (1977), 403

Am. Min. 63 (1978), 1023

Am. Min. 63 (1978), 1023

Am. Min. 46 (1961), 1520

Min. Mag. 43 (1980), 1053

Am. Min. 63 (1978), 1023

Min. Mag. 33 (1962), 253

Am. Min. 63 (1978), 1023

Am. Min. 63 (1978), 1023

Min. Mag. 43 (1980), 1055

Min. Mag. 43 (1980), 1053

Min. Mag. 33 (1962), 261

Min. Mag. 43 (1980), 1055

Min. Mag. 33 (1962), 262

Min. Mag. 36 (1967), 133

Min. Mag. 33 (1962), 261

este artigo

Am. Min. 62 (1977), 403

Min. Mag. 36 (1967), 133

Min. Mag. 36 (1968), 1144

Min. Mag. 36 (1968), 1144

Min. Mag. 38 (1971), 103

Am. Min. 62 (1977), 403

Min. Mag. 43 (1980), 1055

Min. Mag. 36 (1968), 1144

Min. Mag. 33 (1962), 261

Min. Mag. 36 (1967), 133

Min. Mag. 36 (1968), 1144

Min. Mag. 36 (1968), 1144

Am. Min. 63 (1978), 1023

Am. Min. 50 (1965), 2110

Am. Min. 63 (1978), 1023

Min. Mag. 38 (1971), 102

Am. Min. 63 (1978), 1023

este artigo

Min. Mag. 33 (1962), 261

Am. Min. 63 (1978), 1023

Am. Min. 63 (1978), 1023 Am. Min. 63 (1978), 1023 este artigo

Min. Mag. 33 (1962), 262

Min. Mag. 33 (1962), 261

Am. Min. 63 (1978), 1023

Min. Mag. 36 (1967), 133

Min. Mag. 43 (1980), 1053

Am. Min. 63 (1978), 1023

Am. Min. 63 (1978), 1023

Am. Min. 63 (1978), 1023

Am. Min. 63 (1978), 1023

Am. Min. 49 (1964), 448

Min. Mag. 43 (1980), 1055

Min. Mag. 43 (1980), 1055

Am. Min. 62 (1977), 403

Am. Min. 67 (1982), 156

Am. Min. 47 (1962), 783

Am. Min. 47 (1962), 398

Min. Mag. 33 (1962), 261

Am. Min. 53 (1968), 1065

Am. Min. 63 (1978), 1023

Can. Min. 12 (1973), 219 


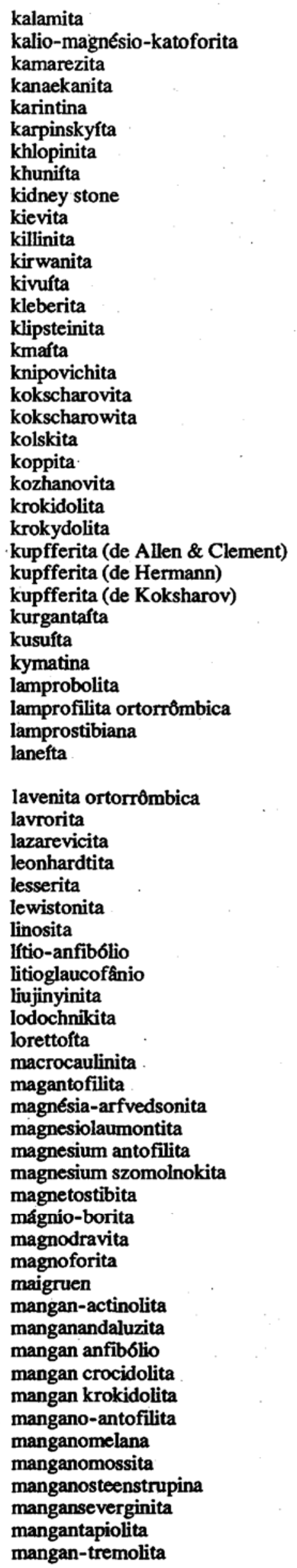

tremolita

richterita com $\mathrm{Ti}(\mathrm{IV})$ e $\mathrm{K}$

brochantita

hornblenda, freqüentemente pargasf́tica

mistura

samarskita $-(\mathrm{Y})$

iranita

actinolita

cummingtonita

hidromuscovita

hornblenda alterada impura

neotocita

alumoidrocalcita

anfib6lio edenftico

anfibólio edenf́tico

lizardita + sepiolita

pirocloro

karnasurtita -(Ce)

crocidolita

crocidolita

magnésio-antofilita

antofilita com $\mathrm{Cr}$

anfibblio antofilítico com $\mathrm{Cr}$

tyretskita com $\mathrm{Sr}+$ celestina

wakefieldita -(Ce)

asbesto

oxi-hornblenda

melanostibita

ferro-hornblenda pargasftica ou

hornblenda pargasftica com Fe(II)

diopsidio com $\mathrm{Cr}$

starkeyíta

inderita

fluorapatita com $\mathrm{CO}_{3}$

oxi-ferri-kaersutita ou oxi-kaersutita com Fe(III)

anfibblio com $\mathrm{Li}$, holmquistita e clinoholmquistita

holmquistita

uytenbogaardtita

brannerita

magnesio-antofilita

magnésio-arfvedsonita

magnesio-antofilita

jacobsita

suanita

richterita com Ti(TV) e K

actinolita com Mn(II)

andaluzita com $\mathrm{Mn}$ (II)

rodonita

riebeckita com Mn(II)

riebeckita com Mn(II)

tirodita

romanechita

manganocolumbita

manganotapiolita

tremolita com Mn(II)
Am. Min. 63 (1978), 1023

Am. Min. 63 (1978), 1023

Am. Min. 50 (1965), 1450

Min. Mag. 46 (1982), 514

Am. Min. 63 (1978), 1023

Am. Min. 57 (1972), 1006

Am. Min. 57 (1972), 329

Am. Min. 61 (1976), 186

Am. Min. 63 (1978), 1023

Am. Min. 63 (1978), 1023

Min. Mag. 48 (1984), 566

Am. Min. 63 (1978), 1023

Min. Mag. 33 (1962), 261

este artigo

Min. Mag. 42 (1978), 279

Min. Mag. 36 (1967), 133

Am. Min. 61 (1976), 341

Am. Min. 63 (1978), 1023

Am. Min. 63 (1978), 1023

Am. Min. 59 (1974), 212

Am. Min. 62 (1977), 403

Min. Mag. 33 (1962), 262

Am. Min. 63 (1978), 1023

Am. Min. 63 (1978), 1023

Am. Min. 63 (1978), 1023

Am. Min. 63 (1978), 1023

Am. Min. 63 (1978), 1023

Min. Mag. 46 (1982), 514

Bull. Min. 109 (1986), 30

Am. Min. 63 (1978), 1023

Am. Min. 63 (1978), 1023

Min. Mag. 36 (1968), 1144

Am. Min. 53 (1968), 1779

Am. Min. 63 (1978), 1023

Min. Mag. 36 (1968), 1144

N. Jb. Min. Mh. (1979), 189

Min. Mag. 33 (1962), 261

Min. Rec. 6 (1975), 144

Min. Mag. 33 (1962), 262

Min. Mag. 42 (1978), 282

Am. Min. 63 (1978), 1023

Am. Min. 63 (1978), 1023

Am. Min. 63 (1978), 1023

este artigo

Am. Min. 48 (1963), 1419

Am. Min. 64 (1979), 1303

Min. Mag. 43 (1980), 1055

Am. Min. 63 (1978), 1023

Am. Min. 63 (1978), 1023

Min. Mag. 36 (1967), 133

Am. Min. 63 (1978), 1023

Min. Mag. 33 (1962), 261

Am. Min. 58 (1973), 562

Am. Min. 48 (1963), 915

Min. Mag. 36 (1968), 1144

Am. Min. 63 (1978), 1023

Min. Mag. 43 (1980), 1055

Am. Min. 63 (1978), 1023

este artigo

Am. Min. 63 (1978), 1023

Am. Min. 63 (1978), 1023

Am. Min. 63 (1978), 1023

Am. Min. 63 (1978), 1023

Min. Mag. 46 (1982), 513

Min. Mag. 33 (1962), 262

Min. Mag. 33 (1962), 261

Min. Mag. 38 (1971), 103

Am. Min. 70 (1985), 217

Am. Min. 63 (1978), 1023 
manganuralita marignacita marmairolita matorolita mbozif́ta medmontita melaconita melnikovita mendeleeyvita mendelejevita metajennita metaliebigita metalomonosovita metamurmannita metasimpsonita metastrengita mindigita minguettita miomirita miropolskita mispíquel miyashiroita mohsita montasita montdorita mossita mountain wood mozambikita mrazekita mumbita munkforssita munkrudita murgocita nakaséfta namaqualita natrongrammatita natronrichterita naurodita nefrita nenadkevita neodigenita neotantalita nicolita niobozirconolita niobpirocloro niobtantalpirocloro niquelemelama niquelita nitroglauberita noonkanbahita noralita nordenskiöldita nuolaíta obruchevita octaedrita oligisto olovotantalita ondrejita opsimose orizita orniblenda ortita orto-armalcolita ortolomonosovita orto-riebeckita ortose ortozoisita oryzita osannita osumilita $-(\mathbf{K}, \mathbf{M g})$ magnésio-arfvedsonita com $\mathrm{Mn}$ (II)

cério-pirocloro -(Ce)

richterita com $\mathrm{Mn}$ (II)

taramita com $K$

crisocola + mica

tenorita

greigita

betafita

betafita

beta-lomonosovita

microlita

fosfossiderita

heterogenita

estilpnomelana

arsenopirita

crichtonita

grunerita asbestiforme

ferrocolumbita com $\mathrm{Ta}$

asbesto

plumbomicrolita

apatita com Mn

cianita

cianotriquita

richterita

richterita com $\mathrm{Mn}(\mathrm{I})$

álcali-anfibslio

actinolita

mistura

digenita

microlita

niquelina

zirkelita

pirocloro

pirocloro/microlita

niquelina

darapskita

ferro-hornblenda

tremolita

mistura

itropirocloro $-(\mathrm{Y})$

anatásio

hematita

huntita + magnesita

neotocita

epistilbita

hornblenda

allanita

lomonosovita

riebeckita

ortoclásio

epistilbita

riebeckita
Am. Min. 63 (1978), 1023

Am. Min. 62 (1977), 403

Am. Min. 63 (1978), 1023

Min. Mag. 38 (1971), 103

Am. Min. 63 (1978), 1023

Am. Min. 54 (1969), 994

Min. Mag. 43 (1980), 1053

Min. Mag. 46 (1982), 513

Am. Min. 62 (1977), 403

Am. Min. 62 (1977), 403

Min. Mag. 36 (1968), 1144

Min. Mag. 38 (1971), 103

Am. Min. 48 (1963), 1413

Min. Mag. 36 (1967), 133

Am. Min. 62 (1977), 403

Min. Mag. 43 (1980), 1053

Min. Mag. 33 (1962), 253

Am. Min. 54 (1969), 1223

Min. Mag. 43 (1980), 1055

Min. Mag. 43 (1980), 1055

Min. Mag. 43 (1980), 1053

Min. Mag. 36 (1968), 1144

Can. Min. 17 (1979), 635

Am. Min. 63 (1978), 1023

este artigo

Min. Mag. 43 (1979), 553

Am. Min. 63 (1978), 1023

Min. Mag. 33 (1962), 261

Min. Mag. 43 (1980), 1055

Am. Min. 62 (1977), 403

Am. Min. 49 (1964), 1778

Am. Min. 49 (1964), 1778

Min. Mag. 43 (1980), 1055

Min. Mag. 33 (1962), 261

Min. Mag. 32 (1961), 737

Am. Min. 63 (1978), 1023

Am. Min. 63 (1978), 1023

Am. Min. 63 (1978), 1023

Am. Min. 63 (1978), 1023

Am. Min. 62 (1977), 1261

Min. Mag. 43 (1980), 1053

Am. Min. 62 (1977), 403

Min. Mag. 43 (1980), 1053

Am. Min. 62 (1977), 403

Am. Min. $62(1977), 403$

Am. Min. 62 (1977), 403

Min. Mag. 33 (1962), 261

Min. Mag. 43 (1980), 1053

Am. Min. 55 (1970), 776

Min. Mag. 36 (1968), 1144

Am. Min. 63 (1978), 1023

Am. Min. 63 (1978), 1023

Am. Min. 62 (1977), 403

Am. Min. $62(19.77), 403$

Min. Mag. 43 (1980), 1053

Min. Mag. 43 (1980), 1053

Min. Mag. 36 (1967), 133

Am. Min. 49 (1964), 1502

Min. Mag. 42 (1978), 279

Am. Min. 57 (1972), 592

Am. Min. 63 (1978), 1023

este artigo

Min. Mag. 43 (1980), 1055

Am. Min. 48 (1963), 1413

Am. Min. 63 (1978), 1023

Min. Mag. 43 (1980), 1053

Min. Mag. 38 (1971), 103

Am. Min. 57 (1972), 592

Am. Min. 63 (1978), 1023

Min. Mag. 43 (1980), 1055 


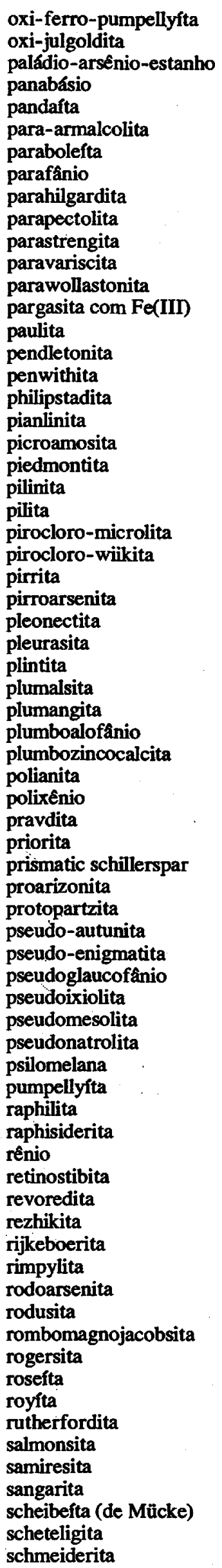

pumpellyita -(FeIII)

julgoldita -(FeIII)

tetraedrita

bário-pirocloro

hilgardita-3Tc

magnésio-hastingsita com Na e Mn(II)

\section{carpatita}

neotocita

ferro-hornblenda com Fe(III)

antofilita com $\mathrm{Fe}(\mathrm{III})$

piemontita

bavenita

actinolita pseudomorfa

pirocloro ou microlita

mistura

berzelifta

hedifano

mistura

mistura

pirolusita

britolita alterada

esquinita $-(Y)$

antofilita

glaucofânio ou crossita

ixiolita

mesolita

mordenita

romanechita

pumpellyíta $-(\mathrm{Mg})$

tremolita

hematita

magnésio-riebeckita ou magnésio-arfvedsonita

bário-microlita

hornblenda

rodonita

magnésio-riebeckita

churchita $-(\mathbf{Y})$

quartzo

rutherfordina

hureaulita + jahnsita

uranopirocloro com $\mathrm{Pb}(\mathrm{IV})$

fenicocrofta

schmiederita
Can. Min. 12 (1973), 219

Can. Min. 12 (1973), 219

este artigo

Min. Mag. 43 (1980), 1053

Am. Min. 62 (1977), 402

Min. Mag. 43 (1980), 1055

Min. Mag. 43 (1980), 1055

Min. Mag. 36 (1968), 1144

Am. Min. 70 (1985), 636

Min. Mag. 43 (1980), 1055

Min. Mag. 43 (1980), 1055

Min. Mag. 43 (1980), 1055

Min. Mag. 33 (1962), 263

Am. Min. 63 (1978), 1023

Min. Mag. 33 (1962), 261

Am. Min. 54 (1969), 329

Min. Mag. 42 (1978), 279

Am. Min. 63 (1978), 1023

este artigo

Am. Min. 63 (1978), 1023

Min. Mag. 43 (1980), 1053

Min. Mag. 33 (1962), 262

Am. Min. 63 (1978), 1023

Am. Min. $62(1977), 403$

Am. Min. $62(1977), 403$

Am. Min. $62(1977), 403$

Am. Min. 58 (1973), 562

Am. Min. 58 (1973), 562

Am. Min. 58 (1973), 562

Min. Mag. 33 (1962), 262

Min. Mag. 38 (1971), 103

Min. Mag. 43 (1980), 1055

Min. Mag. 43 (1980), 1055

Min. Mag. 38 (1971), 103

Min. Mag. 46 (1982), 513

Can. Min. 13 (1975), 117

Am. Min. 49 (1964), 1501

Am. Min. 51 (1966), 152

Am. Min. 63 (1978), 1023

Min. Mag. 36 (1967), 133

Min. Mag. 38 (1971), 103

Min. Mag. 36 (1968), 1144

Min. Mag. 36 (1968), 1144

Am. Min. 63 (1978), 1023

Can. Min. 14 (1976), 540

Min. Mag. 49 (1985), 103

Min. Mag. 33 (1962), 262

Min. Mag. 46 (1982), 513

Can. Min. 12 (1973), 219

Am. Min. 63 (1978), 1023

Am. Min. 53 (1968), 1060

este artigo

Bull. Min. 97 (1974), 520

Min. Mag. 33 (1962), 262

Min. Mag. 33 (1962), 261

Am. Min. 62 (1977), 403

Am. Min. 63 (1978), 1023

Am. Min. 58 (1973), 562

Am. Min. 63 (1978), 1023

Min. Mag. 36 (1967), 133

Am. Min. 48 (1963), 1168

Min. Mag. 38 (1971), 103

Am. Min. 47 (1962), 1223

Min. Mag. 43 (1980), 1053

Min. Mag. 42 (1978), 309

Am. Min. 62 (1977), 403

Min. Mag. 36 (1967), 133

Am. Min. 56 (1971), 359

Am. Min. 62 (1977), 403

Min. Mag. 43 (1980), 1054 
schoenita

schönita

schuchardtita

schulzenita

sebesita

selenjoseíta

septetalc-clorita

shachialita

shentulita

silbölita

silfbergita

silicato-wiikita

silicomanganberzelifta

silicomonazita

silicorrabdofânio

sillbölita

simpsonita (de Wade \& Prider)

sintagmatita (de Troger, 1952)

sjögrufvita

slavyanskita

sobotkita

soda

soda asbesto

soda hornblenda

soda niter

soda nitre

soda richterita

soda tremolita

sódio-flogopita

sokolovita

soretita

spencita

speziatita

sterretita

stipoverita

strahlstein

stratopeíta

strelita

subglaucofânio

sukulaíta

sulfato-monazita

sulunita

sundiusita (de Phillips \& Layton)

sungulita

svidneíta

svitalskita

szechenyifta

szechonyíta

taaffeita-9R

taiyfta

tangaíta

tangenita

tântalo

tântalo-betafita

tântalo-hatchettolita

tântalo-obruchevita

tantalpirocloro

tanzanita

taprobanita

tarasovita

tatarkafta

tavistockita

taylorita

teremkovita

ternovskita

tetrakalsilita

texasita

thalackerita

thierschita

tibergita picromerita

picromerita

vermiculita-clorita

heterogenita com Cu(III)

tremolita

laitakarita

baumita

actinolita

dannemorita

mistura

actinolita

richterita com $T i(T V)$ e $K$

hastingsita com Ti(IV)

carinita

tunisita

saponita

natrāo

magnésio-arfvedsonita

arfvedsonita

nitratina

nitratina

richterita com Mn(II)

richterita

hastingsita com $\mathrm{Mg}$

tritomita $-(\mathrm{Y})$

hornblenda

kolbeckita

actinolita

neotocita

actinolita ou antofilita

crossita

estanomicrolita

lizardita + sepiolita oxi-magnésio-riebeckita

celadonita

richterita

richterita

musgravita

esquinita $-(Y)$

redondita

betafita

uranomicrolita

microlita

taaffeíta

ripidolita

apatita

arcanita com $\mathrm{NH}_{4}$

magnésio-riebeckita

panunzita

antofilita

whewellita

magnésio-hastingsita com $\mathrm{Mn}$ (II) e $\mathrm{Na}$ este artigo

este artigo

Am. Min. 64 (1979), 1334

Min. Mag. 33 (1962), 253

Am. Min. 63 (1978), 1023

Am. Min. 48 (1963), 1421

Am. Min. 61 (1976), 174

este artigo

Min. Mag. 33 (1962), 261

Am. Min. 63 (1978), 1023

Am. Min. 63 (1978), 1023

Am. Min. $62(1977), 403$

Min. Mag. 36 (1968), 1144

Min. Mag. 43 (1980), 1055

Min. Mag. 36 (1967), 133

Am. Min. 63 (1978), 1023

Am. Min. 63 (1978), 1023

Am. Min. 63 (1978), 1023

Am. Min. 58 (1973), 562

Z.V.M.O. $110(1981), 96$

este artigo

Min. Mag. 43 (1980), 1053

Am. Min. 63 (1978), 1023

Am. Min. 63 (1978), 1023

Min. Mag. 43 (1980), 1053

Min. Mag. 43 (1980), 1053

Am. Min. 63 (1978), 1023

Am. Min. 63 (1978), 1023 este artigo

Min. Mag. 33 (1962), 261

Am. Min. 63 (1978), 1023

Am. Min. 51 (1966), 152

Am. Min. 63 (1978), 1023

este artigo

Min. Mag. 36 (1967), 133

Am. 'Min. 63 (1978), 1023

Min. Mag. 42 (1978), 279

Am. Min. 63 (1978), 1023

Am. Min. 63 (1978), 1023

Am. Min. 62 (1977), 403

Min. Mag. $36(1967), 133$

Min. Mag. 33 (1962), 261

Min. Mag. 36 (1968), 1144

Am. Min. 59 (1974), 212

Am. Min. 63 (1978), 1023

Am. Min. 63 (1978), 796

Am. Min. 63 (1978), 1023

Am. Min. 63 (1978), 1023

Am. Min. 69 (1984), 215

Min. Mag. 43 (1980), 1055

Am. Min. 49 (1964), 445

Am. Min. 62 (1977), 403

Am. Min. 47 (1962), 786

Am. Min. 62 (1977), 403

Am. Min. 62 (1977), 403

Am. Min. 62 (1977), 403

Am. Min. 62 (1977), 403

Min. Mag. 43 (1980), 1055

Min. Mag. 46 (1982), 514

Am. Min. 67 (1982), 394

Am. Min. 50 (1965), 2111

Min. Mag. 37 (1969), 123

Can. Min. 23 (1985), 259

Min. Mag. 38 (1971), 103

Am. Min. 63 (1978), 1023

N. Jb. Min. Mh. (1985), H7, 322

Am. Min. 67 (1982), 156

Am. Min. 63 (1978), 1023

Am. Min. 47 (1962), 786

Am. Min. 63 (1978), 1023 
titanobetafita

titano-esquinita

titano-hornblenda

titanomicrolita

titano-obruchevita

titanopirocloro

titano-rabdofânio

toddita

tonerdehaltiger strahlstein

torendrikita

torgadolinita

torio-esquinita

tozalita

transvaalita

tremolita-glaucofânio

trifânio

trudellita

tsavolita

tschermakita actinolftica

tschermakita esmaragdítica

tschernichewita

tucanita

turita

tynita

tyretskita

udokanita

uduminelita

ufertita

uigita

uralita

uranglimmer

uranmica

urano-anatásio

ureyíta

uzbekita

vallachita

vallef́ta

vanuranilita

velikita

vernadskita

viridina

waldheimita

walleriana

warthaíta

wathlingita

wehrlita

weibyeíta

weilerita

weinschenkita (de Laubman)

weinschenkita (de Murgoci)

\section{westgrenita}

wiikita

wilkefta

wittingita

wolframoixiolita

woodfordita

yamatóita

yanzhongita

yenshanita

yftisita

yokosukafta

zeiringita

zeyringita

zillerita

zillerthita

zincalunita

zincblenda

zinco-manganês-cummingtonita

zirconolita betafita

enigmatita

itrobetafita $-(Y)$

mistura

columbita + samarskita

tremolita

magnésio-riebeckita

heterogenita

richterita

espodumênio

natroalunita + cloraluminita

grossulária

magnésio-ou ferro-hornblenda

tschermakita ou hornblenda tschermakítica anfibólio de $\mathrm{Na}$

tyretskita-1Tc

davidita-(La)

thomsonita + girolita

actinolita pseudomorfa

uranita

uranita

cosmocloro

volborthita

antofilita com $\mathrm{Ca}$ e $\mathrm{Mn}$ (II)

antlerita

andalusita com $\mathrm{Mn}$ (II)

richterita

hornblenda

cosalita + galena

kieserita

mistura

bastnäsita + ancilita

churchita $-(Y)$

ferri-magnésio-hornblenda ou

magnésio-hastingsita

bismuto-microlita

mistura

apatita/flúor-ellestadtita

neotocita

ettringita

kotulskita

vysotskita

nsutita

aragonita + auricalcita

aragonita + auricalcita

actinolita

actinolita

esfalerita

zinco-tirodita

zirkelita
Am. Min. 62 (1977), 403

Min. Mag. 36 (1967), 133

Am. Min. 63 (1978), 1023

Am. Min. 62 (1977), 403

Am. Min. $62(1977), 403$

Am. Min. 62 (1977), 403

Min. Mag. 36 (1967), 133

Am. Min. 47 (1962), 1363

Am. Min. 63 (1978), 1023

Am. Min. 63 (1978), 1023

Min. Mag. 43 (1980), 1055

Min. Mag. 36 (1968), 1144

Min. Mag. 43 (1980), 1055

Min. Mag. 33 (1962), 253

Am. Min. 63 (1978), 1023

Min. Mag. 43 (1980), 1053

Am. Min. 57 (1972), 1317

este artigo

Am. Min. 63 (1978), 1023

Am. Min. 63 (1978), 1023

Am. Min. 63 (1978), 1023

Min. Mag. 36 (1968), 1144

Min. Mag. 36 (1968), 1144

Min. Mag. 36 (1967), 133

Am. Min. 70 (1985), 636

Min. Mag. 43 (1980), 1055

Min. Mag. 39 (1974), 929

Am. Min. 49 (1964), 447

Min. Mag. 33 (1962), 262

Am. Min. 63 (1978), 1023

Min. Mag. 43 (1980), 1053

Min. Mag. 43 (1980), 1053

Min. Mag. 36 (1968), 1144

este artigo

Am. Min. 50 (1965), 2111

Min. Mag. 38 (1971), 103

Am. Min. 63 (1978), 1023

Min. Mag. 36 (1968), 1144

Min. Mag. 43 (1980), 1055

Am. Min. 46 (1961), 146

Zts. Krist. 155 (1981), 8

Am. Min. 63 (1978), 1023

Am. Min. 63 (1978), 1023

Am. Min. 49 (1964), 1501

Am. Min. 47 (1962), 811

Am. Min. 69 (1984), 215

Am. Min. 49 (1964), 1154

Min. Mag. 36 (1967), 133

Min. Mag. 46 (1982), 513

Am. Min. 63 (1978), 1023

Am. Min. 62 (1977), 403

Am. Min. 62 (1977), 403

Min. Mag. 46 (1982), 514

Min. Mag. 42 (1978), 279

Min. Mag. 43 (1980), 1055

Min. Mag. 33 (1962), 262

Min. Mag. 36 (1967), 133

Min. Mag. 43 (1980), 1055

Min. Mag. 43 (1980), 1055

este artigo

Am. Min. 49 (1964), 448

Am. Min. 48 (1963), 1184

Am. Min. 48 (1963), 1184

Am. Min. 63 (1978), 1023

Am. Min. 63 (1978), 1023

Min. Mag. 36 (1967), 133

Min. Mag. 43 (1980), 1053

Am. Min. 63 (1978), 1023

Am. Min. 62 (1977), 403 
zirita

zirsita zirkelita

gibbsita
Am. Min. 47 (1962), 1223

Min. Mag. 36 (1967), 133

Apêndice 2 - Nomenclatura revisada para minerais de terras-raras

NOME ORIGINAL
agardita
agardita-(La)
allanita
allanita
allanita-(Y)
ancilita
ashcroftina
bastnäsita
bastnäsita-(La)
bastnäsita-(Y)
bijvoetita
braitschita
britolita
britolita-(Y)
calcio-ancilita
calkinsita
cappelenita
caysichita
cebafta
cerianita
cério-pirocloro
cerita
cerotungstita
chernovita
chevkinita
chukhrovita
chukhrovita-(Ce)
churchita
cordylita
daqingshanita
davidita
davidita
davidita
donnayita
esquinita
esquinita-(Nd)
esquinita-(Y)
euxenita
fergusonita
fergusonita-beta
fergusonita-beta-(Ce)
fergusonita-beta-(Nd)
florencita
florencita-(La)
florencita-(Nd)
fluocerita
fluocerita-(La)
formanita
gadolinita
gadolinita-(Ce)
gagarinita
gysinita
hellandita
hidroxil-bastnäsita
hidroxil-bastnäsita-(Nd)
hingganita
hingganita-(Yb)
huanghoíta
iimoríta
ilimaussita
itrialita
itrobetafita
itrocolumbita
itrocrasita
itropirocloro
itrotantalita
itrotungstita
joaquinita
kainosita

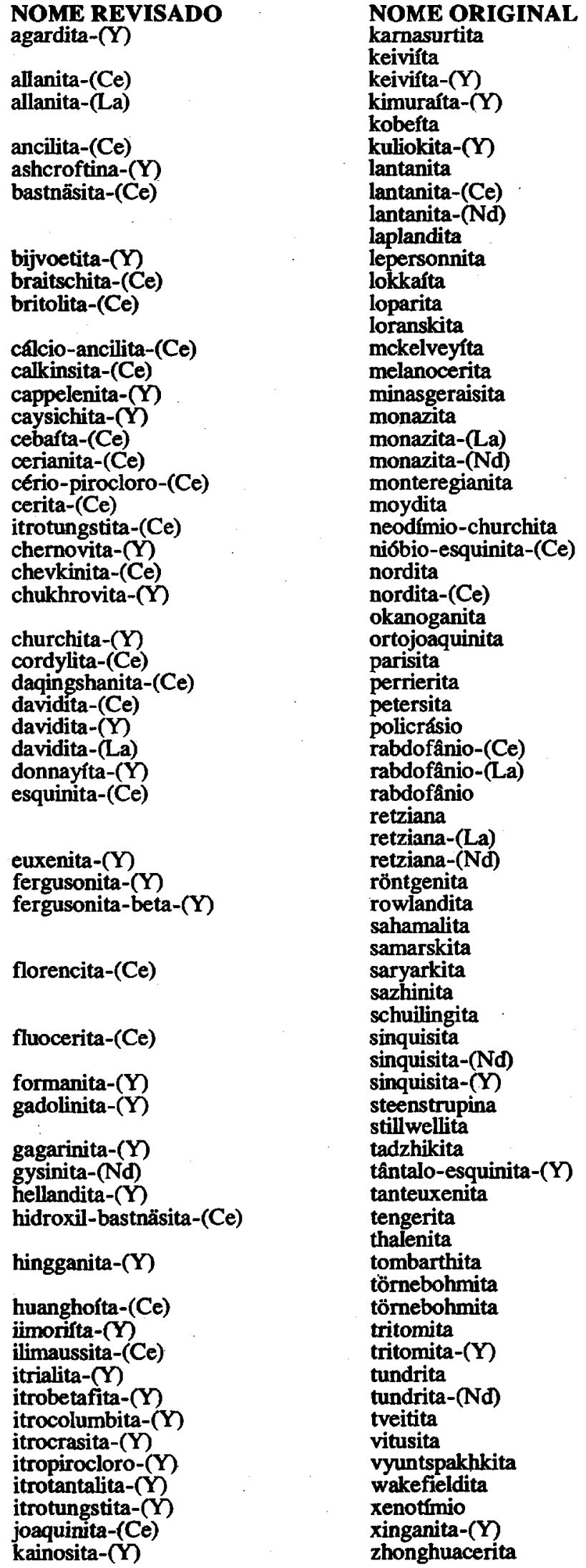

\author{
NOME REVISADO \\ karnasurtita-(Ce) \\ keiví́ta-(Yb) \\ kobeíta-(Y) \\ lantanita-(La) \\ laplandita-(Ce) \\ lepersonnita-(Gd) \\ lokkafta-(Y) \\ loparita-(Ce) \\ loranskita-(Y) \\ mckelveyíta-( $(Y)$ \\ melanocerita-(Ce) \\ minasgeraisita-(Y) \\ monazita-(Ce) \\ monteregianita-( $(\mathbf{Y})$ \\ moydita- $(\mathrm{Y})$ \\ churchita-(Nd) \\ nordita-(La) \\ okanoganita-(Y) \\ ortojoaquinita-(Ce) \\ parisita-(Ce) \\ perrierita-(Ce) \\ petersita-(Y) \\ policrásio-( $(Y)$ \\ rabdofânio-(Nd) \\ retziana-(Ce) \\ röntgenita-(Ce) \\ rowlandita-(Y) \\ sahamalita-(Ce) \\ samarskita-(Y) \\ saryarkita-(Y) \\ sazhinita-(Ce) \\ schuilingita-(Nd) \\ sinquisita-(Ce) \\ steenstrupina-(Ce) \\ stillwellita-(Ce) \\ tadzhikita-(Ce) \\ tanteuxenita-( $Y)$ \\ tengerita-( $(Y)$ \\ thalenita-(Y) \\ tombarthita-( $(Y)$ \\ törnebohmita-(Ce) \\ törnebohmita-(La) \\ tritomita-(Ce) \\ tundrita-(Ce) \\ tveitita-(Y) \\ vitusita-(Ce) \\ vyuntspakhkita-( $(Y)$ \\ wakefieldita-(Y) \\ xenotfmio-(Y) \\ zhonghuacerita-(Ce)
}

